Kim-Pong Tam

The Hong Kong University of Science and Technology

This is a pre-print of a manuscript that is now published in Journal of Environmental Psychology. Visit https://doi.org/10.1016/j.jenvp.2021.101754 for the published article (open-access).

Correspondence:

Correspondence concerning this article should be addressed to Kim-Pong Tam, Division of Social Science, The Hong Kong University of Science and Technology, Clear Water Bay, Hong Kong; e-mail: kevintam@ust.hk.

Acknowledgement:

The work described in this study was partially supported by a grant from the Research Grants Council of the Hong Kong Special Administrative Region, China (Project No.

HKUST645311), and a grant from the Hong Kong University of Science and Technology, Hong Kong (Project No. SBI18HS05).

Supplementary document:

Full details of the measures and materials in the five studies reported in the article can be found in the supplementary document. 


\begin{abstract}
Feeling grateful to nature for its bountiful benefits to humans and wanting to give thanks to nature is a familiar theme in personal stories and cultural rituals, but this emotional experience has rarely been understood scientifically. The present research fills this gap by presenting a theory of gratitude to nature. Findings from four correlational studies and one experiment robustly support its propositions. Gratitude to nature can be conceptualized as a form of benefit-triggered gratitude. The distinction between trait and state gratitude to nature was found to be valid, and both forms of gratitude can be reliably measured. Trait gratitude to nature was associated with interpersonal gratitude as well as a number of constructs relevant to the human-nature relationship (e.g., experience with nature, connectedness to nature, anthropomorphism). Also, gratitude to nature strongly and robustly motivated not only intention but also actual performance of pro-environmental behavior. The theory offers novel insights into the understanding of humans' relations with nature and responses to environmental problems. It also suggests potential directions for environmental education and communication.
\end{abstract}

Keywords: gratitude; human-nature relationship; pro-environmental behavior; connectedness to nature; anthropomorphism 
The provisions by nature range from the food, water, and other materials we consume every day, to the recreational, aesthetic, and restorative experiences we often delight in. Anecdotal accounts suggest that feeling grateful to nature for these provisions and thereby wanting to give thanks to nature through protecting the environment is a familiar theme in personal stories and cultural rituals (e.g., Makoto, 1994). Some educators and writers explicitly argue that gratitude is a virtue that can potently drive environmental conservation (e.g., Joldersma, 2009). Although feeling grateful to nature seems familiar, it has escaped researchers' attention. In psychological research, gratitude is mostly understood in interpersonal contexts (e.g., Algoe, 2012). Considering its paradoxical absence in the literature, I present a theory of gratitude to nature in this article. I define the construct as $a$ sense of gratefulness and thankfulness toward nature that is resulted from the recognition that one has benefited from its provisions. In the following, I will discuss its conceptualization, measurement, and ability to motivate engagement in environmental action.

\section{Nature's Benefits}

Humans rely heavily on nature’s benefits. According to the Millennium Ecosystem Assessment (2005), nature’s bounty can be categorized into four types of ecosystem services. Provisioning services refer to materials humans obtain from the environment. Regulating services refer to natural processes that benefit humans (e.g., pollination, water purification). Cultural benefits are nonmaterial benefits such as spiritual enrichment and aesthetic pleasure. Supporting services (e.g., soil formation, water cycling) are natural processes that support the production of the other services.

An alternative framework by the Intergovernmental Science-Policy Platform on Biodiversity and Ecosystem Services identifies 18 categories of nature’s contributions to people (Diaz et al., 2018). One of the categories is "physical and psychological experiences,” which behavioral researchers are no stranger to. For example, health research shows that 
exposure to nature is beneficial to people’s physical health (e.g., Bowler, Buyung-Ali, Knight, \& Pullin, 2010). Psychological studies demonstrate that people recover faster from stress and cognitive fatigue when exposed to nature (e.g., Bratman, Hamilton, \& Daily, 2012). Nature-based suggestions on how to improve living environments have been made accordingly (e.g., biophilic design; Kellert, 2018) .

\section{Gratitude to Nature: Anecdotal Accounts}

Feeling grateful to nature for its provisions and as a result wanting to protect nature in return is commonplace, as evidenced in people's personal stories. For example, during the $30 X 30$ Challenge campaign in May 2016, nearly 13,000 individuals, 821 schools, and 463 workplaces from 68 countries took part to write "love letters" and "thank you letters" to nature (Lindsay, June 6, 2016). Similar letters are countless in people’s blogs or social media posts on the internet. In a typical letter, the writer expresses his/her gratefulness to nature for its provisions, such as the variety of food one can enjoy and landscapes that afford beautiful scenery. The letter often ends with a note on the failure of humans to love nature back and the importance of protecting nature.

Expressing gratitude to nature is a theme behind some cultural rituals. In agricultureoriented cultures, some festivals are rooted in thanksgiving to nature for giving people harvests. In South India, Pongal, one of the most important Hindu festivals of a year, is a four-day festival in which people give thanks to nature (Pongal Festive, n.d.). In Japan, 4 May is officially designated as the Greenery Day, or midori no hi, a day for thanksgiving and showing appreciation and respect to nature. As Japan is an island nation that strongly relies on the ocean's provisions, it is not surprising that there is also the Marine Day, or umi no hi, which falls on 3 July. Expressions of gratitude to nature are also found in the dietary practices in some cultures. In a community in the Republic of Palau, Suzuki and Tachihara (2014) observed that adult and children respondents similarly reported positive replies when asked if 
they were thankful to nature for its food provisions. They also observed that as a result of gratitude, people in the community rarely waste food. In Japan, people always utter two phrases_-itadakimasu and gochisosama - before and after a meal; the meanings of these phrase are rooted in the expression of gratitude toward nature for its blessings, as well as farmers and cooks for their toil (Makoto, 1994).

Gratitude to nature is found in educational materials too. There are books that are aimed to teach children to appreciate nature's bounty and express their thankfulness by being environmentally responsible. Some examples are Thank you, Earth: A love letter to our planet (Sayre, 2018) and Thank you Earth: An ode to Earthday (Aicher, 2017). Some nature schools also consider fostering gratitude toward nature as a goal in their programs (e.g., Olympic Nature Experience, 2020).

In the field of environmental ethics, gratitude to nature is widely discussed (Bardsley, 2013). One suggestion is that gratitude is a virtue that is useful, if not essential, for environmental conservation (Joldersma, 2009). Some further propose that references to the experience of gratitude to nature should be introduced to environmental laws. Loder (2011, p.435) argued that "new law could directly acknowledge human thanks and debts for the varied bounties of the natural world, justifying concomitant legal responsibilities of human beneficiaries.” However, as of today, rarely do existing laws make gratitude to nature explicit, which might lead to a "lack of recognition at best and an attitude of entitlement at worst”.

\section{Theory of Gratitude to Nature}

Gratitude to nature appears to be a familiar experience and has the potential of motivating pro-environmental behavior (PEB). For all that, no formal theory has ever been proposed for understanding this experience. In this article, I develop a theory of gratitude to nature and present empirical evidences in support of its propositions. Next, I will develop my propositions regarding conceptualization, measurement, effects on PEB of gratitude to nature. 
I will then present findings from five studies.

\subsection{Proposition 1: Gratitude to nature is a form of benefit-triggered gratitude}

In the psychological literature, gratitude is predominantly understood as an interpersonal emotion (Algoe, 2012; McCullough, Emmons, \& Tsang, 2002). It refers to a positive emotion in response to the receipt of a benefit that has resulted from an intentional act by another person (Lazarus \& Lazarus, 1994; McCullough et al., 2002). It is more than a mere positive reaction to the benefit; it necessitates an attribution of it to an external source, namely, another person. In this view, gratitude is an emotion targeted at a benefactor. Lambert, Graham, and Fincham (2009) referred to this type of gratitude as benefit-triggered gratitude and "grateful to" gratitude. It is also referred to as interpersonal gratitude (Wood, Froh, \& Geraghty, 2010).

Notably, some conceptualize gratitude as appreciation of the positive experiences one possesses. Such experiences are not limited to beneficial actions intended by another person (Wood et al., 2010). A person may feel grateful for his/her own outstanding academic abilities or the warm sunshine without attributing these experiences to any external source. This form of gratitude is referred to as generalized gratitude (e.g., Lambert et al., 2009).

I conceptualize gratitude to nature as a form of benefit-triggered gratitude, not generalized gratitude, for three reasons. First, the anecdotal accounts reviewed always refer to an experience that involves attribution of some benefits to nature. Second, benefit-triggered gratitude typically motivates its expression through reciprocation toward to the benefactor, while generalized gratitude does not do so (Algoe, 2012; Ma, Tunney, \& Ferguson, 2017). Thus, conceptualizing gratitude to nature as benefit-triggered theoretically allows me to consider its effects on PEB. Third, in laypeople's view, gratitude is prototypically activated in situations that involve benefits they receive from another person. Using a prototype analysis, Lambert et al., (2009) observed that participants considered scenarios involving benefit- 
triggered gratitude to be more central to the experience of gratitude than scenarios involving generalized gratitude; when asked to name instances of gratitude, a majority of participants wrote about benefit-triggered gratitude.

\subsection{Proposition 2: Gratitude to nature is both a state and a trait and is measurable}

There is a distinction between gratitude as an emotional state and an emotional trait (McCullough et al., 2002; Wood et al., 2010). State gratitude refers to episodic experience of gratitude to a benefactor, whereas trait gratitude refers to a stable disposition for experiencing state gratitude. People with high levels of trait gratitude have a lower threshold for experiencing state gratitude. They distinguish themselves in four facets: intensity — when experiencing a benefit, they feel grateful more intensely; frequency—they feel grateful more frequently; span — they feel grateful for a wider variety of benefits they receive; and density— for a single benefit, they feel grateful toward a larger number of people (McCullough et al., 2002).

I argue that a similar distinction can be made for gratitude to nature. State gratitude to nature refers to episodic experience of gratitude to nature. State gratitude is measurable with reference to three gratitude-related adjectives: grateful, thankful, and appreciative (Dunn \& Schweitzer, 2005). Following this procedure, I propose that state gratitude to nature can be assessed by the extent to which an individual feels grateful, thankful, and appreciative toward nature at a specific moment.

Trait gratitude to nature refers to a dispositional tendency to experience state gratitude to nature intensely, frequently, and for a wider variety of nature's benefits (the facet of density is deemed irrelevant, as nature is the only target by definition). Emmons and Crumpler (2000) argued that gratitude as a virtue refers to the disposition to consistently feel and express the emotion of thankfulness. Accordingly, I consider expression as the fourth facet of trait gratitude to nature. That is, individuals with a strong trait gratitude to nature experience state 
gratitude to nature intensely, frequently, and in a wider span, and want to give thanks to nature. Previous works suggest that individual differences regarding trait gratitude are measurable with psychometric scales (McCullough et al., 2002; Watkins et al., 2003). Accordingly, I propose to develop and validate the Trait Gratitude to Nature Scale.

Notably, state gratitude can also be situationally activated (Ma et al., 2017). Experimental studies have demonstrated the effectiveness of inducing state gratitude with a writing task. The procedures typically guide a person to either recall instances wherein they feel thankful to someone (e.g., Dunn \& Schweitzer, 2005) or write a “thank you letter” to someone (e.g., Watkins, Woodward, Stone, \& Kolts, 2003). I expect that gratitude to nature can also be activated through subjecting individuals to similar procedures.

\subsection{Proposition 3: Gratitude to nature is embedded in a conceptual network}

Based on various theoretical perspectives, I argue that gratitude to nature is associated with the following concepts.

\subsubsection{Experience with nature}

For various reasons (e.g., residential location), experience with nature is unevenly distributed across individuals. According to a study in the United Kingdom, $75 \%$ of the time people spent in natural environments was experienced by only $32 \%$ of the population (Cox, Hudson, Shanahan, Fuller, \& Gaston, 2017). Expectedly, people who spend more time in nature tend to experience stronger affiliation with nature (Cox et al., 2017) and less ecophobia (Soga et al., 2020). As conceptualized, gratitude to nature is triggered by the receipt of benefits recognized as provided by nature. It should follow that individuals who have more contact with nature enjoy more opportunities to receive nature’s benefits; they thereby are more likely to experience gratitude to nature.

\subsubsection{Entitlement}

When people think that they are entitled to a benefit, they are less likely to feel grateful 
to the benefactor (Emmons \& Shelton, 2002). For this reason, trait gratitude is negatively associated with narcissism, a trait that is characterized by the illusory belief that one is entitled to special treatment from others (Watkins et al., 2003). Previous studies have shown that some people hold a "mastery” image regarding the role of humans in their relationship with nature (e.g., De Groot, 2012). These individuals think that humans have the right to use and alter nature. I thus expect that gratitude to nature is lower among these individuals who feel entitled to nature’s benefits.

\subsubsection{Anthropomorphism of nature}

For benefit-triggered gratitude to happen, the beneficiary has to not only recognize the benefit but also perceive that the benefactor intentionally delivered the benefit (Lazarus \& Lazarus, 1994). For example, Weinstein, DeHaan, and Ryan (2010) observed that more gratitude was experienced when participants knew that the benefactor's action was intrinsically motivated. Apparently, it seems irrational for people to feel grateful to nature, which is nonhuman and does not have intentions. For this reason, some writers have questioned whether the concept of gratitude is really useful in environmental ethics. As Manela (2018) noted, because it is unreasonable to believe that the ecosystem intentionally benefits particular organisms, the argument that gratitude is an environmental virtue is indefensible.

Objectively, nature's bounty is not intended to benefit humans. Nevertheless, people may subjectively perceive intentions in nature. Anthropomorphism—attribution of humanlike qualities, including intention, to non-humans—is a ubiquitous cognitive experience (Epley, Waytz, \& Cacioppo, 2007). Just as people may dehumanize certain human groups, it is not uncommon for people to anthropomorphize such nonhuman entities as slot machines (Kim \& McGill, 2011) and even social causes (Ahn, Kim, \& Aggarwal, 2013). Recent studies by Tam and colleagues documented the existence of anthropomorphism of nature. Some people tend 
to consider nature as humanlike (Tam, 2013b, 2015, 2019a; Tam, Lee, \& Chao, 2013). Also, some are susceptible to persuasive messages that present nature as a human (Tam, 2014). Accordingly, I expect that individuals who anthropomorphize nature are more ready to perceive intention behind nature's benefits and thereby experience gratitude to nature (see also McCullough, Kilpatrick, Emmons, \& Larson, 2001).

\subsubsection{New ecological paradigm}

Gratitude to nature is expected to motivate PEB (see Proposition 4 below). It follows that it should be associated with a general pro-environmental worldview. Individuals who feel grateful to nature would express their thankfulness through not only engaging in specific environmental action but also adopting a view that emphasizes a harmonious relationship between humans and nature. This worldview can be understood through the concept of new ecological paradigm (NEP; Dunlap, Van Liere, Mertig, \& Jones, 2000). I thus hypothesize a positive association between gratitude to nature and NEP.

\subsubsection{Connectedness to nature}

Humans are wired to navigate social interactions with the help of emotions (Keltner \& Haidt, 1999). For example, shame is an emotion that has evolved to limit the likelihood or severity of devaluation by others. Gratitude also carries social functions. According to the find-remind-and-bind theory, gratitude has revolved to promote relationship formation and maintenance (Algoe, 2012). The experience of gratitude and its expression allow individuals to find new good partners, remind them of existing ones, and help to bind a recipient and a benefactor closer to each other. Accordingly, I consider that gratitude to nature can bind an individual to nature. That is, I expect that individuals who feel thankful to nature would have a stronger sense of connectedness to nature (Mayer \& Frantz, 2004).

\subsubsection{Interpersonal gratitude}

Although gratitude is mostly studied in the interpersonal context, some researchers 
consider that interpersonal gratitude and gratitude toward nonhuman entities may reflect a common psychological tendency (Emmons \& Shelton, 2002). Some writers even put forward that people who do not feel grateful to nature are poorly disposed to experience gratitude to others. As Hill (1983, p.224) put it, “I suspect that the person who feels no such "gratitude” toward nature is unlikely to show proper gratitude toward people.” In this view, interpersonal gratitude and gratitude to nature are expected to be positively associated with each other.

\subsection{Proposition 4. Gratitude to nature motivates pro-environmental behavior}

According to the moral affect theory of gratitude (McCullough et al., 2001), benefittriggered gratitude serves as a moral motive that motivates beneficiaries to engage in act in the interest of the benefactor, typically in the form of reciprocation. Indeed, Bartlett and DeSteno (2006) found that when participants felt grateful toward a confederate for the help received on an experimental task, this feeling, not general positive affect, subsequently led to stronger willingness to help the confederate in return. Tsang (2006) observed that participants who received a favor by another person, compared to participant who received a positive outcome merely by chance, reported a stronger feeling of gratitude and, in turn, allocated more resources to the benefactor. In a recent meta-analysis of 67 studies, a moderate to strong effect of benefit-triggered gratitude on prosocial behavior $(r=.42)$ was reported (Ma et al., 2017).

McCullough et al. (2001) suggested that gratitude prompts people to not only act prosocially to benefactors but also avoid acting destructively toward them. Accordingly, it is reasonable to propose that when feeling grateful toward nature, individuals are motivated to engage in behaviors that benefit the natural world and avoid behaviors that harm it. This proposition is in line with what are observed in the anecdotal accounts and the environmental ethics suggestions reviewed earlier. This proposition has rarely been tested, however. An exception is Naito et al. (2010), wherein Japanese participants reported their levels of 
gratefulness toward some natural entities and support for pro-environmental actions. A positive association was observed. However, Naito et al. (2010) did not make the important distinction between trait gratitude and state gratitude, or consider the conceptual network of gratitude to nature. Methodologically, the influences of potential confounders were not controlled for and the causal effect on PEB was not examined. As a result, evidence of the behavioral effect of gratitude to nature is still equivocal.

\section{The Present Research}

I conducted five studies to test the four propositions. Studies 1 to 4 were correlational. The Trait Gratitude to Nature Scale was developed in Study 1 with a Hong Kong student sample and then validated with a Hong Kong working adult sample, a representative sample in the United States, and another Hong Kong student sample in Studies 2 to 4. In Study 3, the proposed conceptual network of gratitude to nature was tested. In Study 4, the relationship between trait and state gratitude to nature was examined. In all four correlational studies, the association between gratitude to nature and PEB was tested; multiple measures of both selfreport and actual PEB were used. Study 5 was experimental. With a manipulation of gratitude to nature, it afforded a test of its causal effect on PEB.

Full details of the measures and materials in the five studies can be found in the supplementary document. All procedures in these studies were approved by the committee on research practices of the author's institution.

\section{Study 1}

\section{1. $\quad$ Method}

\subsubsection{Participants}

The sample comprised 113 students (51 males, 62 females) from a university in Hong Kong. Their age ranged from 18 to 26 years $($ mean $=20.35$ and SD $=1.65)$. Each participant was compensated HKD30. All participants were Chinese and had been residing in Hong 
Kong for more than 7 years.

This sample size was sufficient for the planned analyses. According to MacCallum, Widaman, Zhang, and Hong (1999), with a small number of factors, if items showed varying communalities (in the range of .2 to .8), a sample of 100 can achieve good recovery of factors. Also, Naito et al. (2010) observed a correlation between gratitude and environmental attitude in the medium range. According to G*Power 3.1.9.2, to detect a correlation at .30 level, with statistical power $=.80$ and alpha $=.05$, a sample of 85 is sufficient.

\subsubsection{Measures}

Participants completed a battery of measures, including the key measures described below. The other measures unrelated to the present research were not reported.

Trait Gratitude to Nature Scale. Fifteen items were written to capture the four facets of gratitude to nature. Three items referred to expression (with phrases such as "give thanks to nature”) to identify individuals who have a desire to express their thankfulness to nature. Three referred to intensity (with phrases such as “a strong sense of gratitude”) to identify individuals who feel grateful to nature intensely. Five referred to span (with phrases such as “a very long list”) to identify individuals who experience gratitude to nature for a wide span of things. Four referred to frequency (with phrases such as "whenever I eat something delicious”) to identify individuals who feel grateful to nature frequently. Participants responded on a 7-point scale (from “strongly disagree” to “strongly agree”).

$P E B$. Two self-report measures were used. The first was a 10 -item subscale from the Environmental Attitudes Inventory (Milfont \& Duckitt, 2010), which assessed environmental activism support (EAS) (e.g., “I would like to support an environmentalist organization”). Participants responded on a 7-point scale (from "strongly disagree” to "strongly agree”) ( $\alpha$ $=$.84). The second measure was PEB intention. Participants reported how likely they would perform 12 behaviors (e.g., recycling things) in near future on a 11 -point scale (from “ $0 \%$, 
certainly will not do it” to 1 “100\%, certainly will do it”) ( $\alpha=.81)$. These behaviors were adopted from past studies (e.g., Tam, 2013a).

\subsection{Results}

I first performed a principal axis factoring analysis on the items of the Trait Gratitude to Nature Scale. The items' communalities ranged from .26 to .73. The scree plot suggested a one-factor structure $($ Eigenvalue $=6.55$, variance explained $=43.68 \%)$. The factor loadings ranged from .40 to .81 . Scale reliability was $\alpha=.91$. Overall, the scale was satisfactory psychometrically.

A scale reliability above .90 implies that there is some "reliability to spare" and shortening the scale is possible (DeVellis, 2003). Thus, for each facet, I selected the two items with highest variance, as these items had stronger capability to discriminate among individuals with different amounts of the construct (DeVellis, 2003). This selection resulted in eight items. A new factor analysis revealed that these items' communalities ranged from .21 to .64 and a one-factor structure was reasonable (Eigenvalue $=3.33$, variance explained $=41.61 \%)$. The factor loadings ranged from .44 to .82 . Scale reliability was .84 . Overall, this shortened, 8-item scale was very satisfactory. It was adopted as the final scale. Table 1 shows the items and the scale's statistics.

With this scale, I examined the association between trait gratitude to nature and PEB. Gratitude was significantly correlated with EAS $(r=.46)$ and PEB intention $(r=.33)$ (ps $<.001$ ). In regression analyses, with age and gender controlled for, gratitude additionally explained $18.7 \%$ of the variance of EAS $(\Delta F(1,109)=26.17, B=.47, S E=.09, p<.001)$ and $7.2 \%$ of the variance of PEB intention $(\triangle F(1,109)=10.02, B=.44, S E=.14, p=.002)$.

In sum, the 8-item Trait Gratitude to Nature Scale was psychometrically sound. Also, trait gratitude to nature significantly predicted PEB. These findings lay a solid groundwork for the following studies. 


\section{Study 2}

Study 2 was aimed to validate the Trait Gratitude to Nature Scale with a sample of working adults. Also, the predictive power of trait gratitude to nature on PEB was examined. Participants' age (more diverse in this sample), gender, and income were controlled for. In Study 1, only self-report, intention-based measures of PEB were used. People may overreport their intention due to social desirability. Also, the similarity of the measurement methods across the key variables may artificially inflate their observed associations (Podsakoff, MacKenzie, Lee, \& Podsakoff, 2003). Thus, in Study 2, an observational measure of actual behavior (i.e., donation to an environmental organization) was added (Clements, McCright, Dietz, \& Marquart-Pyatt, 2015; Tam, 2015, 2019a).

\section{1. $\quad$ Method}

\subsubsection{Participants}

The sample comprised 118 staff members (34 males, 84 females) from a university in Hong Kong. Their age ranged from 22 to 61 years (mean = 33.35 and SD =9.15). Their monthly income ranged from HKD10,000 to HKD200,000 (mean = 42,566.96 and SD = 32,524.32). They had been residing in Hong Kong for at least 7 years. They were recruited through a mass email to all staff members in the university. Each participant was compensated HKD30.

This sample size was sufficient for detecting a correlation of at least medium size and for a confirmatory factor analysis with 8 items, a single factor, and assumed factor loadings at .50 level (Wolf, Harrington, Clark, \& Miller, 2013). Also, assuming that gratitude to nature has a medium predictive power beyond age, gender, and income $\left(f^{2}=.15\right)$, this sample size was also sufficient (required $\mathrm{N}=55$, with statistical power $=.80$ and alpha $=.05$ ).

\subsubsection{Measures}

Participants completed the 8-item Trait Gratitude to Nature Scale $(\alpha=.92)$. They also 
completed EAS measure in Study $1(\alpha=.87)$ and reported their intention to engage in 12 behaviors similar those in Study $1(\alpha=.85)$. As for actual behavior, I presented an opportunity for participants to donate to an environmental organization. At the end of the study, I told participants that they could either take all of their compensation or donate part or all of it to the World Wide Fund for Nature. For those participants who agreed to donate, they indicated the amount. Thus, the donation amount ranged from HKD0 and HKD30. Participants were paid the amount they did not donate.

\subsection{Results}

For the Trait Gratitude to Nature Scale, a confirmatory factor analysis with the maximum likelihood method revealed a one-factor model with good fit (according to CFI, TFI, and SRMR) and acceptable fit (according to RMSEA) (MacCallum, Browne, \& Sugawara, 1996). The items' standardized factor loadings ranged from .74 to .88. Overall, the scale’s structure was confirmed (see Table 1).

Gratitude to nature was significantly associated with both EAS $(r=.46)$ and PEB intention $(r=.30)(p s \leq .001)$. It was also significantly associated with donation $(r=.22, p$ $=.018)$. Controlling for age, gender, and income, gratitude significantly predicted EAS $\left(\Delta R^{2}\right.$ $=19.4 \%, \Delta F(1,107)=27.48, B=.40, S E=.08, p<.001)$, PEB intention $\left(\Delta R^{2}=9.6 \%, \Delta F(1\right.$, $107)=13.37, B=.49, S E=.13, p<.001)$, and donation $\left(\Delta R^{2}=3.8 \%, \Delta F(1,107)=4.38, B=\right.$ 3.10, $S E=1.48, p=.039)$. Figure 1 visualizes a comparison of the standardized regression coefficients of the predictors.

With a working adult sample, the Trait Gratitude to Nature Scale was again found to be psychometrically sound. Also, participants with higher levels of gratitude to nature reported stronger support for the environmental movement and intention to engage in PEB. Furthermore, these participants, when given an opportunity, actually donated more money to an environmental cause. 


\section{Study 3}

Findings regarding human responses to environmental problems need to be validated cross-culturally (Tam \& Chan, 2017; Tam \& Milfont, 2020). Study 3 was aimed to replicate the previous findings with a representative sample from a different culture. The proposed conceptual network of trait gratitude to nature was tested. The unique predictive power of the trait beyond its correlates in this network was also tested. As in Study 2, I used both selfreport and observational measures of PEB.

\subsection{Method}

\subsubsection{Participants}

Participants were recruited from an online panel called Prolific Academic. Previous studies have confirmed the data quality of this panel (Peer, Brandimarte, Samat, \& Acquisti, 2017). Interlocked quota sampling was used to obtain a sample that approximated the adult population in the United States with respect to gender, age, and ethnicity. There were 496 participants (male: 48.79\%, female: 51.21\%; age 18-24: 13.31\%, age 25-34: 19.76\%, age 3544: 17.94\%, age 45-54: 16.53\%, age 55-64: 18.55\%, age 65+: 13.71\%; Asian: 7.26\%, Black: 13.10\%, Mixed: 3.83\%, Other: 3.63\%, White: 72.18\%). Each participant was compensated GBP2.

This sample size was sufficient for detecting a medium correlation and the planned confirmatory factor analysis. Assuming that trait gratitude to nature bears only a small predictive power $\left(f^{2}=.02\right)$ beyond its correlates that are known to be robustly predictive of PEB (e.g., NEP, connectedness to nature), this sample size was still sufficient (required $\mathrm{N}=$ 395, with statistical power $=.80$ and alpha $=.05$ ).

\subsubsection{Measures}

In addition to the Trait Gratitude to Nature Scale $(\alpha=.94)$, participants responded to three items regarding experience with nature (e.g., "Nowadays, I spend a lot of time in the 
natural environment”) ( $\alpha=$.72) and five items regarding entitlement (e.g., "Humans are entitled to the resources nature provides”) ( $\alpha=.81$ ). For anthropomorphism of nature, participants answered the five questions ("To what extent does nature have a mind of its own/intentions/free will/consciousness/emotional experience?”) on the Anthropomorphism of Nature Scale (Tam, 2013, 2019a) on an 11-point scale (from "not at all” to "very much”) ( $\alpha$ $=.93)$. For ecological worldview, participants completed a 6-item version of the NEP scale (Hawcroft \& Milfont, 2010) ( $\alpha=$.74). For connectedness to nature, the graphical Inclusion of Nature in Self scale (Schultz, 2001) was used. Participants picked the picture (from seven options) that described the closeness of their relationship with nature the best. For interpersonal gratitude, participants completed the Gratitude Questionnaire-6 (McCullough et al., 2002) ( $\alpha=$.87). Except those specified, participants responded on a 7-point scale (from “strongly disagree” to “strongly agree”).

As for PEB, participants completed the EAS measure $(\alpha=.93)$ and reported their intention to engage in the 12 behaviors in Study 2 on a 5-point likelihood scale (from "not at all likely” to "extremely likely”) ( $\alpha=.87)$. As in Study 2, I observed donation to an environmental organization. I told participants that they were awarded a bonus of GBP0.50 and they could either take all of it or donate part or all of it to the World Wide Fund for Nature. Participants indicated the amount they would like to donate (from GBP0.00 to GBP0.50). They were paid the amount they did not donate.

\subsubsection{Data quality checks}

Although there has been evidence of the ability of online samples to generate highquality data, concerns persist. Thus, I adopted three data quality checks. Nevertheless, as dropping potentially problematic participants tends to introduce sampling bias or other threats to external validity (Oppenheimer, Meyvis, \& Davidenko, 2009), in the following, I present results based on the full sample. In the supplementary document, I present details about the 
checks and the results with the potentially problematic participants excluded. The findings are highly consistent across the two sets of analyses.

\subsection{Results}

The one-factor model exhibited good fit (based on CFI, TFI, and SRMR) and acceptable fit (based on RMSEA) for the Trait Gratitude to Nature Scale. The items' standardized factor loadings ranged from .76 to .90. The scale’s structure was confirmed (see Table 1).

Replicating Study 2, gratitude to nature was significantly correlated with EAS ( $r=.54)$, PEB intention $(r=.55)$, and donation $(r=.26)(p s<.001)$. Also, as proposed, trait gratitude to nature was associated positively with experience with nature $(r=.54)$, anthropomorphism of nature $(r=.44)$, NEP $(r=.16)$, inclusion of nature in self $(r=.63)$, and interpersonal gratitude $(r=.42)$, and negatively with entitlement $(r=-.26)(p s \leq .001)$.

Although there was apparent overlap between trait gratitude to nature and some of the other constructs (inclusion of nature in self, in particular), the following regression analyses revealed that they were conceptually distinct from each other, as gratitude to nature exhibited strong and robust unique predictive power. In Model 1, only demographic variables were included as predictors. In Model 2, the other constructs were added. In Model 3, gratitude to nature was added (see Table 2). Across the measures of PEB, adding the psychological variables in Model 2 significantly improved the prediction by $9.3 \%$ to $36.4 \%$. Most of these variables were significant predictors when predicting EAS and PEB intention. When it came to predicting donation, only NEP and anthropomorphism of nature were significant. This pattern suggests the difference between predicting self-report PEB intention and predicting actual behavior (Clements et al., 2015) and affirms the importance of including actual donation as an additional measure.

In Model 3, trait gratitude to nature improved the prediction by $7.5 \%$ for EAS, $7.5 \%$ for PEB intention, and $2.0 \%$ for donation. It was consistently a significant predictor, suggesting 
the incremental validity of gratitude to nature. Notably, comparing the standardized coefficients of the various predictors reveals that gratitude to nature always had the biggest effect among all variables examined ( $\beta \mathrm{s}=.43, .43$, and .22 , respectively); the second strongest predictor was consistently $\operatorname{NEP}(\beta s=.23, .19$, and .21 , respectively). Figure 2 visualizes the comparison of the standardized coefficients.

In sum, with a representative sample from a different cultural context, the proposed conceptual network of trait gratitude to nature was supported. Also, replicating Studies 1 and 2, gratitude strongly and robustly predicted PEB, despite the control of a wide range of demographic and psychological variables that were supposedly strongly predictive of PEB (e.g., NEP, inclusion of nature in self).

\section{Study 4}

As proposed, there is a distinction between trait and state gratitude to nature, and individuals with high levels of trait gratitude to nature should exhibit a lower threshold for state gratitude to nature. This idea was tested in Study 4. Participants completed the Trait Gratitude to Nature Scale. Two weeks later, participants read an article about the provisions of nature and reported their evaluation of it and their emotional experience at the specific moment. This prospective design was less susceptible to the biases introduced by the item

context effects (e.g., predictors and outcomes measured at the same time point), which could artificially inflate observed associations (Podsakoff et al., 2003). The associations between trait and state gratitude to nature and PEB were also examined.

\section{1. $\quad$ Method}

\subsubsection{Participants}

The sample comprised 106 students (51 males, 52 females, 3 unreported) from a university in Hong Kong. Their age ranged from 18 to 24 years (mean $=20.61$ and SD = 1.51). They participated for partial course fulfillment. All participants had been residing in 
Hong Kong for at least 7 years. This sample size was sufficient for detecting a medium correlation and the planned confirmatory factor analysis.

\subsubsection{Measures}

In Part 1, participants completed the Trait Gratitude to Nature Scale $(\alpha=.93)$. Two weeks later, in Part 2, participants were asked to read an article at their own pace and then answer some questions. The article, titled "Benefits from Nature”, introduced the provisions by nature. It was 438-word long, illustrated with photos, and developed based on the concept of ecosystem services and nature’s contributions to people. It began with a paragraph highlighting that human living relies heavily on nature's benefits, which can be categorized into three types: provisioning, regulating, and cultural. It then briefly introduced each type of benefits and illustrated them with examples. After reading the article, participants answered two questions about their understanding of it and how much they enjoyed reading it on a 11point scale (from “not at all” to “very much”). Next, they responded to three items of state

gratitude to nature (e.g., "Right now, I feel thankful to the natural environment”) on a 7-point scale (from "strongly disagree” to "strongly agree”) ( $\alpha=.92)$.

At the end, participants completed the EAS measure used previously $(\alpha=.82)$ and reported their intention to perform the 12 behaviors used in Studies 2 and 3 on a 11-point scale (from "not at all” to $10=$ "very much”) ( $\alpha=$.89). Because the participants were unpaid, the donation measure was not used.

\subsection{Results}

The one-factor model exhibited good fit (based on CFI, TFI, and SRMR) and acceptable fit (based on RMSEA) for the Trait Gratitude to Nature Scale. The items’ standardized factor loadings ranged from .74 to .88 (see Table 1 ).

As proposed, trait gratitude to nature was strongly associated with state gratitude to nature $(r=.55, p<.001)$. Trait gratitude to nature was also significantly associated with 
enjoyment of reading the article $(r=.21, p=.034)$ but not understanding of it $(r=-.02, p$ $=.882$ ). In a regression model with age and gender controlled for, trait gratitude to nature explained $25.7 \%$ of the variance of state gratitude to nature $(\triangle F(1,99)=39.03, B=.45, S E$ $=.07, p<.001)$ and $3.6 \%$ of the variance of enjoyment $(\triangle F(1,99)=3.71, B=.36, S E=.19, p$ $=.057)$.

Trait gratitude to nature was significantly associated with EAS $(r=.33)$ and PEB intention $(r=.40)(p s \leq .001)$. State gratitude to nature was also significantly associated with EAS $(r=.25, p=.009)$ and PEB intention $(r=.32, p=.001)$. Controlling for age and gender, trait gratitude to nature significantly improved prediction of $\mathrm{EAS}\left(\Delta R^{2}=9.9 \%, \Delta F(1,99)=\right.$ 11.64, $B=.23, S E=.07, p=.001)$ and PEB intention $\left(\Delta R^{2}=15.7 \%, \Delta F(1,99)=18.80, B\right.$ $=.49, S E=.11, p<.001)$. Similarly, state gratitude to nature improved the prediction of EAS $\left(\Delta R^{2}=4.2 \%, \Delta F(1,99)=4.61, B=.18, S E=.08, p=.034\right)$ and PEB intention $\left(\Delta R^{2}=10.8 \%\right.$, $\Delta F(1,99)=12.22, B=.48, S E=.14, p=.001)$. When both were included in the model, only trait gratitude to nature was significant $(B=.21, S E=.08, p=.010$ for EAS and $B=.38, S E$ $=.13, p=.005$ for PEB intention); state gratitude to nature was not $(B=.05, S E=.10, p$ $=.636$ and $B=.24, S E=.16, p=.128)$.

When receiving information about nature's benefits, participants who had a stronger disposition of gratitude to nature indeed reported higher levels of momentary feelings of gratitude toward nature. They also enjoyed reading such information more. These findings support the expected association between trait and state gratitude to nature. Also, both trait and state gratitude to nature were associated with PEB. This association was more robust for trait gratitude to nature, even though it was measured two weeks before the PEB measures.

\section{Study 5}

Despite the positive findings in the four studies, the causal effect of gratitude to nature on PEB remains untested. Study 5 addressed this issue. Participants were led to either think 
about gratitude to nature, gratitude to other people, objectively how nature benefits humans, or the destructive forces of nature. I expected that participants in the gratitude to nature condition would subsequently report a stronger PEB intention than participants in the other conditions. This hypothesis was tested with a planned contrast. Positive findings would suggest that the causal effect of gratitude to nature is specific and not reducible to the effect of interpersonal gratitude, objective recount of natural provisions, or other forms of the human-nature relationship.

\section{1. $\quad$ Method}

\subsubsection{Participants}

One hundred and fifty-three students from a university in Hong Kong participated for partial course fulfillment. They had been residing in Hong Kong for at least 7 years. After dropping two participants who failed to comply with the experimental instructions (see below), the final sample comprised 151 participants (90 males, 60 females, 1 unreported). Their age ranged from 18 to 24 years $($ mean $=20.40$ and $S D=1.61)$.

With an assumed medium effect size in a planned contrast with four groups, statistical power $=.80$, and alpha $=.05$, a sample of 128 was needed. I recruited a slightly larger sample to account for potential compliance failure in some participants. The final sample size was sufficient.

\subsubsection{Procedures}

Participants were first randomly assigned to one of the four conditions. In the gratitude to nature condition, they were led to recall instance in which they felt grateful and thankful to nature. In the gratitude to people condition, they were given similar instructions, but the focus was shifted to other people. In the objective recount condition, participants were asked to think objectively and identify cases to illustrate how humans' living is supported by nature. In the natural destruction condition, participants were guided to recall cases to illustrate how 
humans' living can be destroyed by natural forces. All participants wrote their responses on a A4-sized paper at their own pace. When they were done, they completed the EAS measure ( $\alpha$ $=.85)$ and a PEB intention measure similar to those used earlier $(\alpha=.83)$. Because the participants were unpaid, the donation measure was not used.

Two manipulation checks were used. After completing the PEB measures, participants responded to the three state gratitude to nature items in Study $4(\alpha=.90)$ and three items that measured indebtedness to nature (e.g., "Right now, I feel I owe a great deal to the natural environment”) ( $\alpha=.87$ ). Indebtedness is another emotion that is triggered by the receipt of benefits from others (McCullough et al., 2001). It is distinct from gratitude, however, as it is a negative emotion arising from the felt obligation to repay the benefactors and the worry of being unable to do so. Lay people tend to consider indebtedness to be peripheral to their experience of gratitude (Lambert et al., 2009). Measuring indebtedness allowed me to illustrate the distinct effect of the manipulation on gratitude to nature, not other related emotions. Participants responded to these two measures on a 7-point scale (from "strongly disagree” to "strongly agree”). The second check concerned participants’ compliance with the manipulation's instructions. Two research assistants with undergraduate training independently read the writings by all participants and identified compliance failures. There was strong inter-coder reliability: Among the 153 writings, there was only one disagreement, which was resolved after discussion. Two participants were dropped for compliance failure.

\subsection{Results}

The omnibus effect of condition was not significant on gratitude to nature, $F(3,147)=$ $1.65, p=.180$, indebtedness to nature, $F(3,147)=.63, p=.594$, and EAS, $F(3,147)=.30, p$ $=.827$. The omnibus effect of condition on PEB intention was marginally significant, $F(3$, $147)=2.20, p=.091$. Notably, these omnibus tests did not directly test the hypothesis, which concerns a comparison between the gratitude to nature condition and the other conditions. As 
a significant omnibus effect is unnecessary for testing specific, planned comparisons (Hancock \& Klockars, 1996), I proceeded to the planned contrast. A marginally significant effect was found for gratitude to nature, $F(1,147)=3.82, p=.053$, partial eta ${ }^{2}=.03$. A significant effect was found for PEB intention, $F(1,147)=6.18, p=.014$, partial eta ${ }^{2}=.04$. The contrast was not significant for indebtedness to nature $(p=1.000)$ and EAS $(p=.486)$. Table 3 shows the descriptive statistics of the four conditions.

In sum, the findings hint that the manipulation was effective. Participants in the gratitude to nature condition reported higher levels of state gratitude to nature, but not state indebtedness to nature, than did the remaining participants. These participants also reported higher levels of PEB intention. This finding suggests that the causal effect of gratitude to nature on PEB. Notably, this effect was not observed for EAS. One possible reason is that environmental activism, unlike PEB in one's private sphere of life, is less susceptible to the influences of momentary factors. Environmental activism is public and collective in nature, and thereby susceptible to the broader social contexts such as generalized trust and political institutions (Tam, 2019b). Also, environmental activism is typically costly and necessitates strong environmental concern (Stern, 2000). For these reasons, there is plausibly less room for one's attitude toward environmental activism to be swayed by such momentary factors as an experimental manipulation. This speculation remains to be explored in future.

\section{General Discussion}

Humans rely heavily on the contributions by nature. Feeling grateful to nature for these contributions and wanting to give thanks to nature is a familiar experience for some individuals and cultures and a potential pathway to environmental ethics. Surprisingly, this experience has rarely been understood scientifically. The present research fills this gap. From the five studies, I obtained robust support for the theory of gratitude to nature presented. This theory offers novel insights into the understanding of humans' relations with nature and 
responses to environmental problems. I discuss these insights in the following.

\subsection{Understanding the human-nature relationship}

Scientists have identified a myriad of nature’s contributions to humanity (Diaz et al., 2015; Millennium Ecosystem Assessment, 2005). Rarely understood, however, is how humans think and feel about these provisions. In addition to identifying the countless ways through which humans benefit from nature, this question is also important to answer: When people recognize a benefit that comes from nature (e.g., tasty meal, stunning natural scene), how do they respond?

There is a worry that emphasizing the benefits nature brings to humans runs the risk of legitimizing a utilitarian and anthropocentric view of nature, which may lead to commodification of nature and backfire on environmental conservation (Chan et al., 2016). The theory of gratitude to nature implies that this worry does not necessarily hold true. The reviewed anecdotal accounts suggest the possibility of feeling grateful toward nature in response to its benefits among some individuals and cultures. The present theory allows us to explicate this possibility at the individual level. The overarching proposition is that gratitude to nature is a form of benefit-triggered gratitude targeted at the natural world (Proposition 1). When coming into realization that their living is reliant on the many provisions by nature, some people feel grateful to nature and some do not; these inter-individual differences reflect a stable trait, which can be reliably measured (Propositions 2). The theory hints at where this trait comes from; it is associated with how frequently the person has contact with nature, how strongly he/she feels entitled to nature's benefits, to what extent he/she perceives nature as humanlike, etc. (Proposition 3). The theory also allows us to anticipate its behavioral consequences; the experience of gratitude to nature robustly motivates thanksgiving to nature in the form of environmental actions (Proposition 4).

The theory echoes recent calls for attention to the diversity of relational models 
conditioning humans’ interactions with nature (Muradian \& Pascual, 2018). In the understanding of human-nature relations, nature is often regarded as a victim of humans' interference (e.g., Rees, Klug, \& Bamberg, 2015; Tam, 2013b). There is also a focus wherein humans are seen as victims in the face of natural disasters (e.g., Reser \& Swim, 2011). Some studies have understood nature as a source of reverence, fear, and existential threat too (e.g., Bixler \& Floyd, 1997). The present research allows us to not only consider an additional layer of the human-nature relationship, wherein nature is a benefactor and humans are beneficiaries, but also theorize the chain of actions that this aspect of the relationship may involve.

People may consider nature as humanlike, even though it is objectively questionable. This phenomenon implies that it is possible for an individual to relate to nature in ways that are similar to how he/she relates to other people (Tam, 2013b). For example, when nature is seen as humanlike, people tend to experience a stronger sense of connectedness to it (Tam et al., 2013) and exhibit emotions that are predominantly understood to be interpersonal, such as empathy (Tam, 2013b, 2015) and guilt (Tam, 2019a). It seems viable to theorize humans’ interactions with nature with reference to existing psychological concepts regarding interpersonal relationships, particularly when anthropomorphism of nature is applied. The present findings add more evidence to this theoretical approach by showing the link between anthropomorphism and gratitude. Notably, some environmental ethics writers have argued that conceptualizing gratitude as an environmental virtue is an indefensible position because it is unreasonable to believe that the ecosystem intentionally benefits humans (Manela, 2018). The present findings speak to the contrary. At the very least, the experience of gratitude to nature does exist, particularly among individuals who subjectively perceive intention in nature.

\subsection{Understanding pro-environmental behavior}


As introduced, there have been suggestions that gratitude to nature is a human virtue and a pathway to conservation ethics (e.g., Joldersma, 2009). The present findings provide empirical support to these suggestions. As observed, gratitude to nature can motivate PEB. In fact, its motivating effect was apparently strong. For instance, in Study 3, it was the strongest predictor of the various PEB outcomes, even when compared to the many known robust predictors such as NEP and connectedness to nature. The effect was strong in the practical sense too. For example, even after controlling for the other factors, a one-point increase in trait gratitude to nature was associated with an increase in donation by HKD3.10 in Study 2 (10.33\% of the compensation participants received) and GBP0.04 in Study 3 (8.00\% of the bonus participants received).

These findings contribute to the debate over whether we protect the environment for humans’ sake (i.e., instrumental values) or nature’s own worth (i.e., intrinsic values) (Chan et al., 2016). This debate presumes a dichotomized view of environmental protection, which is also reflected in the study of environmental attitudes in terms of the contrast between anthropocentrism and ecocentrism (Thompson \& Barton, 1994) or utilization and preservation (Milfont \& Duckitt, 2010). The theory of gratitude to nature implies that this dichotomized view is perhaps incomplete. Indeed, when people recognize the benefits they receive from nature, they have a stronger motivation to engage in environmental protection. However, this motivation is not necessarily rooted in anthropocentric or instrumental considerations. The present findings suggest that the motivation may represent people's desire to express their thankfulness to nature through reciprocity. That is, this motivation is embedded in the benefactor-beneficiary interactions between humans and nature. It is neither anthropocentric nor ecocentric; it is relational. Joining studies showing that some people are motivated to protect the environment because of the identity-related meanings embedded in their relationship with places and natural entities (e.g., Halpenny, 2010), the present research 
suggests the importance of relational values (Klain, Olmsted, Chan, \& Satterfield, 2017). Relational values refer to the meanings that people derive from their relationships with nature. With this concept, we can understand environmental protection as driven by what is preferred and what is seen as appropriate in the relationship with nature; such considerations are not always reducible to the dichotomy between instrumental values and nature's intrinsic worth.

Emotions have been recognized to be a key determinant behind people’s behavioral decisions in the environmental domain (Bissing-Olson, Fielding, \& Iyer, 2016). Research has shown that negative emotions (e.g., fear, guilt, anxiety) can be effective in motivating environmental actions (e.g., Rees et al., 2015), but they can also backfire due to defensive avoidance and moral disengagement (O’Neill \& Nicholson-Cole, 2009; Stern, 2012). Markowitz and Shariff (2012) recognized the importance of positive emotions as opposed to negative emotions when engaging the public in climate change, as positive emotions can not only motivate PEB but also feed wellbeing. In line with recent studies regarding such positive emotions as pride (e.g., Bissing-Olson et al., 2016) and hope (e.g., Ojala, 2012), the present findings add gratitude, an emotion that has rarely been considered, to the study of environmental action.

\subsection{Practical implications}

Some have identified the role of emotions in environmental education (Sobel, 1996). One view is that empathy training is an effective tool. For example, empathy with, and hence protectiveness toward, entities in the natural world can be instilled into children through place-based and experience-based activities such as contact with animals and perspective taking exercises (Sobel, 1996). Note, however, that empathy is rooted in observations of others' suffering; too much empathy may lead to compassion fatigue and burnout (Figley, 2002). 
The theory of gratitude to nature suggests a novel, complementary route. As introduced, educational materials that are designed to guide children to recognize nature’s bounty and express their thankfulness through environmentally responsible actions are already widely available (e.g., Aicher, 2017; Olympic Nature Experience, 2020). The present findings hint that these materials can be effective. Fostering the development of trait gratitude to nature appears to be a reasonable goal that educators should consider. Educators may couple placebased activities (e.g., nature tours) with such gratitude interventions as “thank you letter” (e.g., Watkins et al., 2003) or gratitude journal-keeping writing (e.g., Emmons \& Stern, 2013). It is expected that over time, not only trait gratitude to nature but also environmentally responsible behavior can be fostered.

Additionally, the present findings hint at the potential of gratitude as a positive emotional appeal in environmental and climate change communication. Guiding message recipients to think about the provisions they receive from the environment and recall their gratefulness to nature for such provisions may effectively promote a pro-environmental orientation at least momentarily for domains that are susceptible to situational influences. This positive appeal can serve as a potent alternative to the conventional use of appeals to negative emotions, which are known to have drawbacks (Stern, 2012).

\subsection{Limitations and future directions}

The present research focuses solely on the experience of gratitude to nature at the individual level. Future studies are needed to understand gratitude to nature at the cultural level. It will be important to know whether there are any cross-cultural differences in the experience of gratitude to nature and its behavioral effects. Testing this idea requires a large sample of cultures. Similarly, it remains to be understood whether personal experience and shared experience of gratitude to nature (e.g., through participation in cultural rituals) are qualitatively different from each other, and whether the latter bears similar behavioral effects. 
To address these questions, ethnographic method is obviously desirable.

As discussed, various emotions are also known to motivate environmental action (e.g., guilt, pride). As the present research is a pioneer investigation into the construct of gratitude to nature, it was mainly aimed to validate some fundamental propositions (including its behavioral effect). Thus, it is beyond the present scope to compare gratitude to nature to these other emotions. Future studies may use experience sampling, for example, to examine how frequently people experience these different emotions (see Bissing-Olson et al., 2016). Survey and experimental studies would also be useful for comparing their behavioral effects.

A strong positive association between connectedness to nature and gratitude to nature was observed in Study 3. It is still uncertain how they are inter-related. As introduced, one interpretation is that gratitude fosters relationship formation, according to the find-remindand-bind theory (Algoe, 2012). In this view, gratitude to nature is a precursor of connectedness to nature and a pathway to a long-term commitment to a harmonious relationship with nature. To examine this conceptual sequence, longitudinal or cross-lagged panel design will be useful.

\section{Conclusion}

While gratitude to nature is a familiar experience and some thinkers and educators are already advocating for its potency to drive environmental conservation, scientific research on this experience has been lacking. The present research successfully develops and validates four fundamental propositions for understanding this experience. Researchers interested in how humans relate to nature are recommended to consider these propositions seriously. 


\section{References}

Ahn, H. K., Kim, H. J., \& Aggarwal, P. (2014). Helping fellow beings: Anthropomorphized social causes and the role of anticipatory guilt. Psychological Science, 25(1), 224-229. https://doi.org/10.1177/0956797613496823

Aicher, J. (2017). Thank you Earth: An ode to Earthday. StoryMothers, Inc.

Algoe, S. B. (2012). Find, remind, and bind: The functions of gratitude in everyday relationships. Social and Personality Psychology Compass, 6(6), 455-469.

https://doi.org/10.1111/j.1751-9004.2012.00439.x

Bardsley, K. (2013). Mother nature and the mother of all virtues: On the rationality of feeling gratitude toward nature. Environmental Ethics, 35(1), 27-40.

https://doi.org/10.5840/enviroethics20133514

Bartlett, M. Y., \& DeSteno, D. (2006). Gratitude and prosocial behavior: Helping when it costs you. Psychological Science, 17(4), 319-325. https://doi.org/10.1111/j.1467-

9280.2006.01705.x

Bissing-Olson, M. J., Fielding, K. S., \& Iyer, A. (2016). Experiences of pride, not guilt, predict pro-environmental behavior when pro-environmental descriptive norms are more positive. Journal of Environmental Psychology, 45, 145-153.

https://doi.org/10.1016/j.jenvp.2016.01.001

Bixler, R. D., \& Floyd, M. F. (1997). Nature is scary, disgusting, and uncomfortable. Environment and Behavior, 29(4), 443-467. https://doi.org/10.1177/001391659702900401

Bowler, D. E., Buyung-Ali, L., Knight, T. M., \& Pullin, A. S. (2010). Urban greening to cool towns and cities: A systematic review of the empirical evidence. Landscape and Urban Planning, 97(3), 147-155. https://doi.org/10.1016/j.landurbplan.2010.05.006

Bratman, G. N., Hamilton, J. P., \& Daily, G. C. (2012). The impacts of nature experience on human cognitive function and mental health. Annals of the New York Academy of Sciences, 1249(1), 118-136. https://doi.org/10.1111/j.1749-6632.2011.06400.x

Chan, K. M., Balvanera, P., Benessaiah, K., Chapman, M., Díaz, S., Gómez-Baggethun, E., ... \& Luck, G. W. (2016). Opinion: Why protect nature? Rethinking values and the environment. Proceedings of the National Academy of Sciences, 113(6), 1462-1465.

https://doi.org/10.1073/pnas.1525002113

Clements, J. M., McCright, A. M., Dietz, T., \& Marquart-Pyatt, S. T. (2015). A behavioural measure of environmental decision-making for social surveys. Environmental Sociology, 1(1), 27-37. https://doi.org/10.1080/23251042.2015.1020466

Cox, D. T., Hudson, H. L., Shanahan, D. F., Fuller, R. A., \& Gaston, K. J. (2017). The rarity of direct experiences of nature in an urban population. Landscape and Urban Planning, 160, 79-84. https://doi.org/10.1016/j.landurbplan.2016.12.006

de Groot, M. (2012). Exploring the relationship between public environmental ethics and 
river flood policies in western Europe. Journal of Environmental Management, 93(1), 1-9. https://doi.org/10.1016/j.jenvman.2011.08.020

DeVellis, R.F. (2003). Scale development theory and applications. Thousand Oaks, CA: Sage Publications.

Díaz, S., Pascual, U., Stenseke, M., Martín-López, B., Watson, R. T., Molnár, Z., ... \& Polasky, S. (2018). Assessing nature's contributions to people. Science, 359(6373), 270-272. https://doi.org/10.1126/science.aap8826

Dunlap, R. E., Van Liere, K. D., Mertig, A. G., \& Jones, R. E. (2000). New trends in measuring environmental attitudes: Measuring endorsement of the new ecological paradigm: A revised NEP scale. Journal of Social Issues, 56(3), 425-442. https://doi.org/10.1111/0022$\underline{4537.00176}$

Dunn, J. R., \& Schweitzer, M. E. (2005). Feeling and believing: The influence of emotion on trust. Journal of Personality and Social Psychology, 88(5), 736-748.

https://doi.org/10.1037/0022-3514.88.5.736

Emmons, R. A., \& Crumpler, C. A. (2000). Gratitude as a human strength: Appraising the evidence. Journal of Social and Clinical Psychology, 19(1), 56-69.

https://doi.org/10.1521/jscp.2000.19.1.56

Emmons, R. A., \& Shelton, C. M. (2002). Gratitude and the science of positive psychology. In C. R. Snyder, \& S. L. Lopez (Eds.), Handbook of positive psychology (pp. 459-471). Oxford University Press.

Emmons, R. A., \& Stern, R. (2013). Gratitude as a psychotherapeutic intervention. Journal of Clinical Psychology, 69(8), 846-855. https://doi.org/10.1002/jclp.22020

Epley, N., Waytz, A., \& Cacioppo, J. T. (2007). On seeing human: a three-factor theory of anthropomorphism. Psychological Review, 114(4), 864-886. https://doi.org/10.1037/0033295X.114.4.864

Figley, C. R. (2002). Compassion fatigue: Psychotherapists' chronic lack of self-care. Journal of Clinical Psychology, 58(11), 1433-1441. https://doi.org/10.1002/jclp.10090

Halpenny, E. A. (2010). Pro-environmental behaviours and park visitors: The effect of place attachment. Journal of Environmental Psychology, 30(4), 409-421.

https://doi.org/10.1016/j.jenvp.2010.04.006

Hancock, G. R., \& Klockars, A. J. (1996). The quest for $\alpha$ : Developments in multiple comparison procedures in the quarter century since. Review of Educational Research, 66(3), 269-306. https://doi.org/10.3102/00346543066003269

Hawcroft, L. J., \& Milfont, T. L. (2010). The use (and abuse) of the new environmental paradigm scale over the last 30 years: A meta-analysis. Journal of Environmental psychology, 30(2), 143-158. https://doi.org/10.1016/j.jenvp.2009.10.003

Hill, T. E. (1983). Ideals of human excellence and preserving natural environments. 
Environmental Ethics, 5(3), 211-224. https://doi.org/10.5840/enviroethics19835327

Jann, B. (2014). Plotting regression coefficients and other estimates. The Stata Journal 14(4), 708-737. https://doi.org/10.1177/1536867X1401400402

Joldersma, C. W. (2009). How can science help us care for nature? Hermeneutics, fragility, and responsibility for the earth. Educational Theory, 59(4), 465-483.

https://doi.org/10.1111/j.1741-5446.2009.00331.x

Kellert, S. R. (2018). Nature by design: The practice of biophilic design. Yale University Press.

Keltner, D., \& Haidt, J. (1999). Social functions of emotions at four levels of analysis. Cognition \& Emotion, 13(5), 505-521. https://doi.org/10.1080/026999399379168

Kim, S., \& McGill, A. L. (2011). Gaming with Mr. Slot or gaming the slot machine? Power, anthropomorphism, and risk perception. Journal of Consumer Research, 38(1), 94-107. https://doi.org/10.1086/658148

Klain, S. C., Olmsted, P., Chan, K. M., \& Satterfield, T. (2017). Relational values resonate broadly and differently than intrinsic or instrumental values, or the New Ecological Paradigm. PLoS ONE, 12(8), e0183962. https://doi.org/10.1371/journal.pone.0183962

Lambert, N. M., Graham, S. M., \& Fincham, F. D. (2009). A prototype analysis of gratitude: Varieties of gratitude experiences. Personality and Social Psychology Bulletin, 35(9), 11931207. https://doi.org/10.1177/0146167209338071

Lazarus, R. S., \& Lazarus, B. N. (1994). Passion and reason: Making sense of our emotions. Oxford University Press.

Lindsay. (2016, June 6). 30 days of nature: The David Suzuki Foundation's 30×30 Challenge wrap-up. The Love Lettering Project.

https://loveletteringproject.com/30x30davidsuzukifoundationwrapup/

Loder, R. E. (2011). Gratitude and the environment: Toward individual and collective ecological virtue. The Journal Jurisprudence, 10, 383-435.

Ma, L. K., Tunney, R. J., \& Ferguson, E. (2017). Does gratitude enhance prosociality? A meta-analytic review. Psychological Bulletin, 143(6), 601-635.

https://doi.org/10.1037/bul0000103

MacCallum, R. C., Browne, M. W., \& Sugawara, H. M. (1996). Power analysis and determination of sample size for covariance structure modeling. Psychological Methods, 1(2), 130-149. https://doi.org/10.1037/1082-989X.1.2.130

MacCallum, R. C., Widaman, K. F., Zhang, S., \& Hong, S. (1999). Sample size in factor analysis. Psychological Methods, 4(1), 84-99. https://doi.org/10.1037/1082-989X.4.1.84

Makoto, N. (1994). Rice imports and implications. Japan Quarterly, 41(1), 16-24. 
Manela, T. (2018). Gratitude to Nature. Environmental Values, 27(6), 623-644. https://doi.org/10.3197/096327118X15343388356356

Markowitz, E. M., \& Shariff, A. F. (2012). Climate change and moral judgement. Nature Climate Change, 2(4), 243-247. https://doi.org/10.1038/nclimate1378

Mayer, F. S., \& Frantz, C. M. (2004). The connectedness to nature scale: A measure of individuals' feeling in community with nature. Journal of Environmental Psychology, 24(4), 503-515. https://doi.org/10.1016/j.jenvp.2004.10.001

McCullough, M. E., Emmons, R. A., \& Tsang, J. A. (2002). The grateful disposition: A conceptual and empirical topography. Journal of Personality and Social Psychology, 82(1), 112-127. https://doi.org/10.1037/0022-3514.82.1.112

McCullough, M. E., Kilpatrick, S. D., Emmons, R. A., \& Larson, D. B. (2001). Is gratitude a moral affect? Psychological Bulletin, 127(2), 249-266. https://doi.org/10.1037/0033-

2909.127.2.249

Milfont, T. L., \& Duckitt, J. (2010). The environmental attitudes inventory: A valid and reliable measure to assess the structure of environmental attitudes. Journal of Environmental Psychology, 30(1), 80-94. https://doi.org/10.1016/j.jenvp.2009.09.001

Millennium Ecosystem Assessment. (2005). Ecosystems and human well-being: Synthesis. Washington, DC: Island Press.

Muradian, R., \& Pascual, U. (2018). A typology of elementary forms of human-nature relations: A contribution to the valuation debate. Current Opinion in Environmental Sustainability, 35, 8-14. https://doi.org/10.1016/j.cosust.2018.10.014

Naito, T., Matsuda, T., Intasuwan, P., Chuawanlee, W., Thanachanan, S., Ounthitiwat, J., \& Fukushima, M. (2010). Gratitude for, and regret toward, nature: Relationships to proenvironmental intent of university students from Japan. Social Behavior and Personality, 38(7), 993-1008. https://doi.org/10.2224/sbp.2010.38.7.993

Ojala, M. (2012). Hope and climate change: The importance of hope for environmental engagement among young people. Environmental Education Research, 18(5), 625-642. https://doi.org/10.1080/13504622.2011.637157

Olympic Nature Experience. (2020). Welcome. Olympic Nature Experience. https://www.olympicnatureexperience.org/

O’Neill, S., \& Nicholson-Cole, S. (2009). "Fear won't do it”: Promoting positive engagement with climate change through visual and iconic representations. Science Communication, 30(3), 355-379. https://doi.org/10.1177/1075547008329201

Oppenheimer, D. M., Meyvis, T., \& Davidenko, N. (2009). Instructional manipulation checks: Detecting satisficing to increase statistical power. Journal of Experimental Social Psychology, 45(4), 867-872. https://doi.org/10.1016/j.jesp.2009.03.009

Peer, E., Brandimarte, L., Samat, S., \& Acquisti, A. (2017). Beyond the Turk: Alternative 
platforms for crowdsourcing behavioral research. Journal of Experimental Social Psychology, 70, 153-163. https://doi.org/10.1016/j.jesp.2017.01.006

Podsakoff, P. M., MacKenzie, S. B., Lee, J. Y., \& Podsakoff, N. P. (2003). Common method biases in behavioral research: A critical review of the literature and recommended remedies. Journal of Applied Psychology, 88(5), 879-903. https://doi.org/10.1037/0021-9010.88.5.879

Pongal Festival. (n.d.). Pongal Festival: The Harvest Festival of South India. http://www.pongalfestival.org/pongal-festival.html

Rees, J. H., Klug, S., \& Bamberg, S. (2015). Guilty conscience: Motivating proenvironmental behavior by inducing negative moral emotions. Climatic Change, 130(3), 439452. https://doi.org/10.1007/s10584-014-1278-X

Reser, J. P., \& Swim, J. K. (2011). Adapting to and coping with the threat and impacts of climate change. American Psychologist, 66(4), 277-289. https://doi.org/10.1037/a0023412

Sayre, A. P. (2018). Thank you, Earth: A love letter to our planet. Greenwillow Books.

Schultz, P. W. (2001). Assessing the structure of environmental concern: Concern for self, other people, and the biosphere. Journal of Environmental Psychology, 21, 1-13.

https://doi.org/10.1006/jevp.2001.0227

Sobel, D. (1996). Beyond ecophobia: Reclaiming the heart in nature education. Great Barrington, MA: The Orion Society and the Myrin Institute.

Soga, M., Evans, M. J., Yamanoi, T., Fukano, Y., Tsuchiya, K., Koyanagi, T. F., \& Kanai, T. (2020). How can we mitigate against increasing biophobia among children during the extinction of experience? Biological Conservation, 242, 108420.

https://doi.org/10.1016/j.biocon.2020.108420

Stern, P. C. (2000). New environmental theories: Toward a coherent theory of environmentally significant behavior. Journal of Social Issues, 56(3), 407-424. https://doi.org/10.1111/0022-4537.00175

Stern, P. C. (2012). Fear and hope in climate messages. Nature Climate Change, 2(8), 572573. https://doi.org/10.1038/nclimate1610

Suzuki, N., \& Tachihara, S. (2014). Role of diet in sustaining the family and community ties. Bulletin of Japanese Society for the Science of Design, 61(1), 1_7-1_16.

Tam, K. P. (2013a). Concepts and measures related to connection to nature: Similarities and differences. Journal of Environmental Psychology, 34, 64-78.

https://doi.org/10.1016/j.jenvp.2013.01.004

Tam, K-P. (2013b). Dispositional empathy with nature. Journal of Environmental Psychology, 35, 92-104. https://doi.org/10.1016/j.jenvp.2013.05.004

Tam, K-P. (2014). Anthropomorphism of nature and efficacy in coping with the environmental crisis. Social Cognition, 32, 278-298. 
Tam, K-P. (2015). Mind attribution to nature and pro-environmental behavior. Ecopsychology, 7, 87-95. https://doi.org/10.1089/eco.2014.0054

Tam, K-P. (2019a). Anthropomorphism of nature, environmental guilt, and pro-environmental behavior. Sustainability, 11(19), 5430. https://doi.org/10.3390/su11195430

Tam, K-P. (2019b). Understanding the psychology X politics interaction behind environmental activism: The roles of governmental trust, density of environmental NGOs, and democracy. Journal of Environmental Psychology, 101330.

https://doi.org/10.1016/j.jenvp.2019.101330

Tam, K-P., \& Chan, H-W. (2017). Environmental concern has a weaker association with proenvironmental behavior in some societies than others: A cross-cultural psychology perspective. Journal of Environmental Psychology, 53, 213-223. https://doi.org/10.1016/j.jenvp.2017.09.001

Tam, K-P., \& Milfont, T. L. (2020). Towards cross-cultural environmental psychology: A state-of-the-art review and recommendations. Manuscript under review.

Tam, K-P., Lee, S-L., \& Chao, M. M. (2013). Saving Mr. Nature: Anthropomorphism enhances connectedness to and protectiveness toward nature. Journal of Experimental Social Psychology, 49, 514-521. https://doi.org/10.1016/i.jesp.2013.02.001

Thompson, S. C. G., \& Barton, M. A. (1994). Ecocentric and anthropocentric attitudes toward the environment. Journal of Environmental Psychology, 14(2), 149-157.

https://doi.org/10.1016/S0272-4944(05)80168-9

Tsang, J. A. (2006). Gratitude and prosocial behaviour: An experimental test of gratitude. Cognition \& Emotion, 20(1), 138-148. https://doi.org/10.1080/02699930500172341

Watkins, P. C., Woodward, K., Stone, T., \& Kolts, R. L. (2003). Gratitude and happiness: Development of a measure of gratitude, and relationships with subjective well-being. Social Behavior and Personality, 31(5), 431-452. https://doi.org/10.2224/sbp.2003.31.5.431

Weinstein, N., DeHaan, C. R., \& Ryan, R. M. (2010). Attributing autonomous versus introjected motivation to helpers and the recipient experience: Effects on gratitude, attitudes, and well-being. Motivation and Emotion, 34(4), 418-431. https://doi.org/10.1007/s11031010-9183-8

Wolf, E. J., Harrington, K. M., Clark, S. L., \& Miller, M. W. (2013). Sample size requirements for structural equation models: An evaluation of power, bias, and solution propriety. Educational and Psychological Measurement, 73(6), 913-934.

https://doi.org/10.1177/0013164413495237

Wood, A. M., Froh, J. J., \& Geraghty, A. W. (2010). Gratitude and well-being: A review and theoretical integration. Clinical Psychology Review, 30(7), 890-905.

https://doi.org/10.1016/j.cpr.2010.03.005 
Table 1. The Trait Gratitude to Nature Scale and its psychometric properties in Studies 1 to 4

\begin{tabular}{|c|c|c|c|c|c|}
\hline & & Study 1 & Study 2 & Study 3 & Study 4 \\
\hline Facet & Item & $\begin{array}{c}\text { Factor loading } \\
\text { (exploratory) }\end{array}$ & \multicolumn{3}{|c|}{ Factor loading (confirmatory) } \\
\hline \multirow[t]{2}{*}{ Expression } & 1. I want to give thanks to nature for its support to my life. & .68 & .82 & .85 & 83 \\
\hline & 2. It is important for me to do something to show my thankfulness to the natural world for the resources I can use. & .64 & .83 & .78 & .77 \\
\hline \multirow[t]{2}{*}{ Intensity } & 3. I am deeply grateful to nature for all it provides me with. & .82 & .92 & .82 & .82 \\
\hline & 4. I have a strong sense of gratitude toward the natural world for its support to me. & .81 & .90 & .90 & .88 \\
\hline \multirow[t]{2}{*}{ Span } & 5. If I were to list the reasons why I feel grateful toward nature, it would be a very long list. & .56 & .77 & .79 & .81 \\
\hline & 6. As I look back on my life, I feel that I have been richly blessed by the natural world. & .62 & .81 & .79 & .74 \\
\hline \multirow[t]{2}{*}{ Frequency } & 7. Even something as simple as seeing a beautiful flower can make me feel grateful toward nature. & 48 & .69 & .76 & .75 \\
\hline & 8. Whenever I eat something delicious, I feel grateful toward the natural world for its provisions. & .44 & .52 & .76 & .75 \\
\hline \multicolumn{2}{|l|}{ Scale mean } & 4.86 & 5.07 & 5.14 & 5.30 \\
\hline \multicolumn{2}{|l|}{ Scale SD } & .78 & 1.04 & 1.25 & .90 \\
\hline \multicolumn{2}{|l|}{ Scale reliability } & .84 & .92 & .94 & .93 \\
\hline \multirow[t]{7}{*}{ Model fit indices } & Chi-square & & 42.77 & 87.34 & 48.25 \\
\hline & df & & 20 & 20 & 20 \\
\hline & $p$ & & .002 & $<.001$ & $<.001$ \\
\hline & CFI & & .96 & .98 & .96 \\
\hline & TLI & & .95 & .97 & .94 \\
\hline & SRMR & & .05 & .03 & .04 \\
\hline & RMSEA & & .10 & .08 & .11 \\
\hline
\end{tabular}

Notes. The instruction of the scale read: "The statements below describe some feelings toward nature. For each statement, please check a box to indicate your agreement or disagreement with it. ( 1 = strongly disagree; $2=$ disagree; $3=$ mildly disagree; $4=$ neither disagree or agree; $5=$ mildly agree; 6 = agree; 7 = strongly agree).” 
Table 2. Results of the regression analyses in Study 3

\begin{tabular}{|c|c|c|c|c|c|c|c|c|c|}
\hline \multirow[b]{2}{*}{ Predictors } & \multicolumn{3}{|c|}{ Environmental activism support } & \multicolumn{3}{|c|}{ PEB intention } & \multicolumn{3}{|c|}{ Donation } \\
\hline & Model 1 & Model 2 & Model 3 & Model 1 & Model 2 & Model 3 & Model 1 & Model 2 & Model 3 \\
\hline Gender $(0=$ female, $1=$ male $)$ & $-.34 * *(.12)$ & $-.14(.10)$ & $-.10(.09)$ & $-23 * * *(.07)$ & $-.14 *(.06)$ & $-.12 *(.06)$ & $-.05 *(.02)$ & $-.03(.02)$ & $-.03(.02)$ \\
\hline Age & $-.01(.004)$ & $-.01 * * *(.003)$ & $-.01 * * *(.003)$ & $.01 * *(.002)$ & $.004(.002)$ & $.004 *(.002)$ & $.002 *(.001)$ & $.002 * *(.001)$ & $.002 * *(.001)$ \\
\hline Asian & $.34(.38)$ & $.51(.31)$ & $.54(.29)$ & $.18(.22)$ & $.22(.19)$ & $.24(.18)$ & $-.02(.06)$ & $.01(.06)$ & $.02(.06)$ \\
\hline Black & $.29(.35)$ & $.39(.28)$ & $.47(.26)$ & $.14(.20)$ & $.15(.17)$ & $.20(.16)$ & $-.04(.06)$ & $-.02(.05)$ & $-.01(.05)$ \\
\hline Mixed & $.48(.43)$ & $.10(.35)$ & $.17(.33)$ & $.18(.25)$ & $-.02(.22)$ & $.02(.20)$ & $-.11(.07)$ & $-.10(.07)$ & $-.10(.07)$ \\
\hline White & $.11(.32)$ & $-.02(.26)$ & $.06(.24)$ & $.13(.18)$ & $.04(.16)$ & $.08(.15)$ & $-.03(.05)$ & $-.01(.05)$ & $-.004(.05)$ \\
\hline Experience with nature & & $.22 * * *(.05)$ & $.12 * *(.04)$ & & $.14^{* * *}(.03)$ & $.08 * *(.03)$ & & $-.01(.01)$ & $-.02(.01)$ \\
\hline Entitlement & & $-.24 * * *(.06)$ & $-.19 * * *(.05)$ & & $-.06(.03)$ & $-.03(.03)$ & & $-.01(.01)$ & $-.004(.01)$ \\
\hline Anthropomorphism of nature & & $.02(.02)$ & $-.03(.02)$ & & $.02 *(.01)$ & $-.01(.01)$ & & $.01 * *(.003)$ & $.01(.003)$ \\
\hline New ecological paradigm & & $.30 * * *(.06)$ & $.27 * * *(.06)$ & & $.14 * * *(.04)$ & $.13^{* * *}(.03)$ & & $.04 * * *(.01)$ & $.04 * * *(.01)$ \\
\hline Inclusion of nature in self & & $.17 * * *(.04)$ & $.04(.04)$ & & $.07 * *(.03)$ & $-.01(.03)$ & & $.01(.01)$ & $-.001(.01)$ \\
\hline Interpersonal gratitude & & $.07(.05)$ & $-.06(.05)$ & & $.07 * *(.03)$ & $.001(.03)$ & & $.01(.01)$ & $-.003(.01)$ \\
\hline Trait gratitude to nature & & & $.45^{* * *}(.06)$ & & & $.26^{* * *}(.03)$ & & & $.04 * *(.01)$ \\
\hline$R^{2}$ of model & $3.1 \%$ & $39.5 \%$ & $47.0 \%$ & $4.2 \%$ & $29.5 \%$ & $37.1 \%$ & $3.3 \%$ & $12.5 \%$ & $14.6 \%$ \\
\hline$R^{2}$ change from previous model & $3.1 \%$ & $36.4 \%$ & $7.5 \%$ & $4.2 \%$ & $25.3 \%$ & $7.5 \%$ & $3.3 \%$ & $9.3 \%$ & $2.0 \%$ \\
\hline$p$ & .016 & $<.001$ & $<.001$ & .002 & $<.001$ & $<.001$ & .013 & $<.001$ & .001 \\
\hline
\end{tabular}

Notes. ${ }^{* *} p<.001 .{ }^{* *} p<.01 . * p<.05$. The coefficients shown are unstandardized coefficients, with standard errors in brackets. For the ethnicity variables, the reference category was "Other." 
Table 3. Descriptive statistics in Study 5

\begin{tabular}{|c|c|c|c|c|c|c|c|c|c|}
\hline \multirow[b]{2}{*}{ Condition } & \multirow[b]{2}{*}{$\mathrm{N}$} & \multicolumn{2}{|c|}{ State gratitude to nature } & \multicolumn{2}{|c|}{ State indebtedness to nature } & \multicolumn{2}{|c|}{ EAS } & \multicolumn{2}{|c|}{ PEB intention } \\
\hline & & mean & SD & mean & SD & mean & SD & mean & SD \\
\hline Gratitude to nature & 39 & 5.90 & .88 & 4.74 & 1.05 & 4.56 & .77 & 6.66 & 1.25 \\
\hline Gratitude to people & 41 & 5.60 & .99 & 4.94 & 1.19 & 4.49 & .90 & 5.91 & 1.48 \\
\hline Objective recount & 36 & 5.66 & .71 & 4.66 & 1.02 & 4.47 & .69 & 6.04 & 1.28 \\
\hline Natural destruction & 35 & 5.43 & 1.06 & 4.64 & .97 & 4.37 & 1.07 & 6.07 & 1.56 \\
\hline
\end{tabular}


Figure 1. Comparing the standardized regression coefficients of the predictors in Study 2

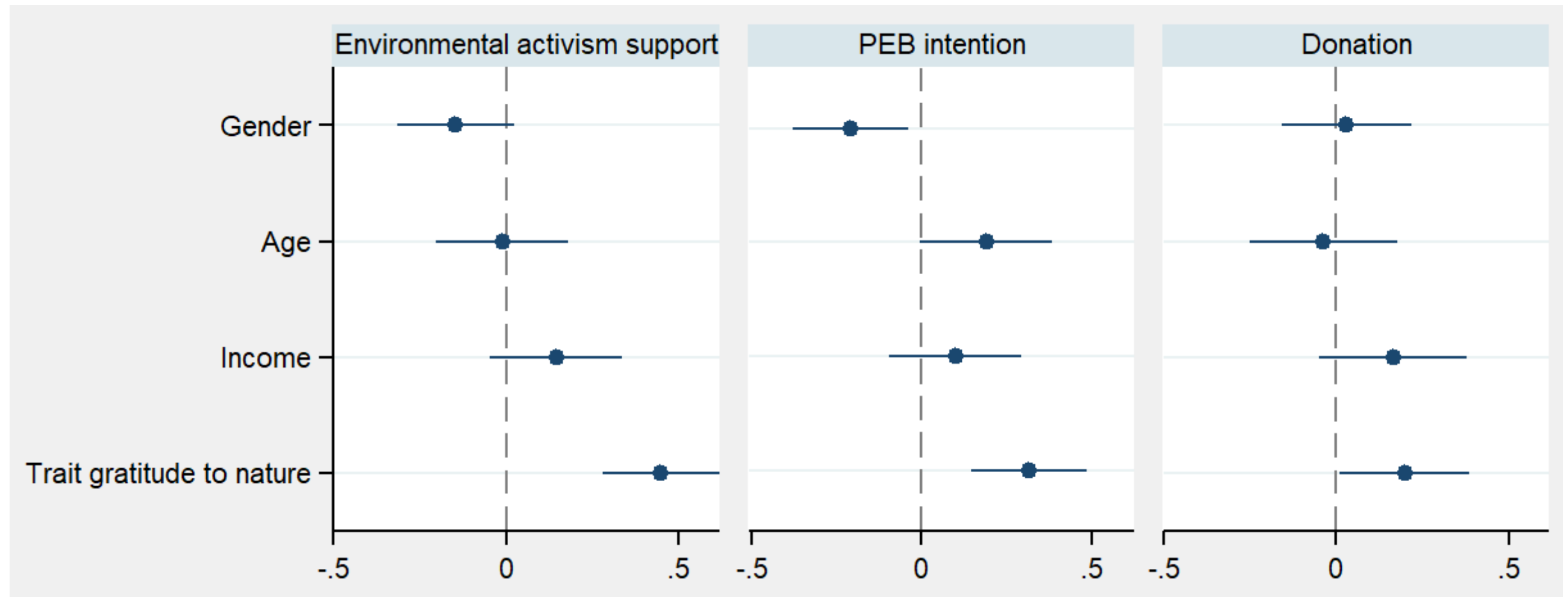

Note. The plot was generated with the coefplot command in Stata developed by Jann (2014). The whiskers stand for 95\% confidence intervals. 
Figure 2. Comparing the standardized regression coefficients of the predictors in Study 3
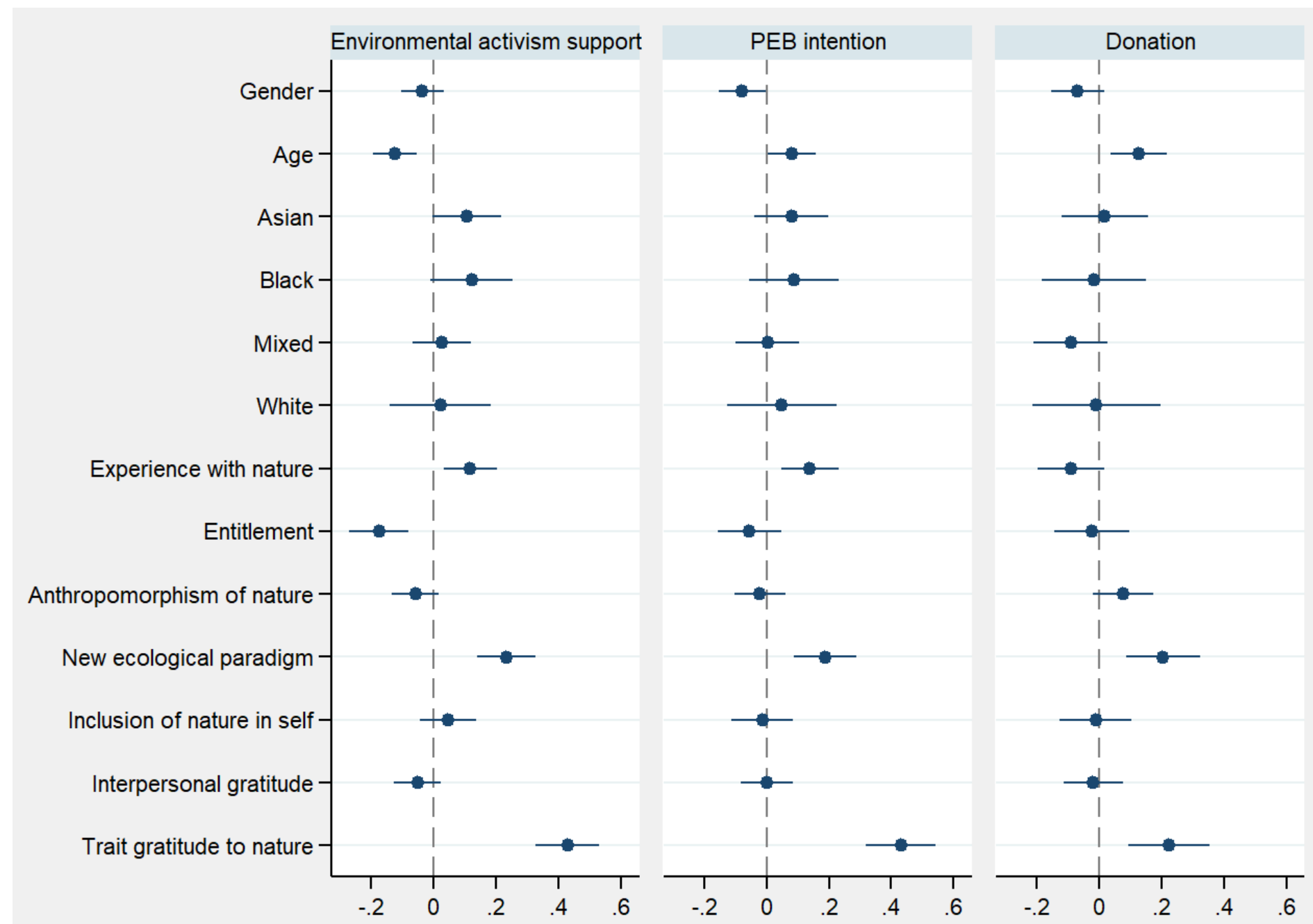

Note. The plot was generated with the coefplot command in Stata developed by Jann (2014). The whiskers stand for 95\% confidence intervals. 